\title{
Are Gender Equality Institutions the Policy Allies of the Feminist Movement? A Contingent 'Yes' in the Spanish Central State
}

\section{Celia Valiente}

This article studies the extent to which gender equality institutions are the policy allies of the feminist movement in Spain. A policy ally of the feminist movement is defined as one that adopts the demands of the movement and includes them in the policy process. This article analyses the role played by the Women's Institute (WI) between 1983 and 2003 in 12 policy debates, in a third of which the WI was an ally of the movement. Two circumstances are identified as necessary for the WI to act as an ally of the feminist movement, whilst other are not strictly necessary but have facilitated the WI acting as a policy ally of the movement.

Keywords: Feminist Movement; Policy Ally; Women's Institute; Women's Policy Agencies; Policy Debates; Spain

\footnotetext{
Are gender equality institutions the policy allies of the feminist movement? Gender equality institutions or women's policy agencies (WPAs) are state units established with the explicit mandate of improving women's status (Stetson \& Mazur 1995). In this article, a 'policy ally' of the movement is defined as an actor that adopts its demands and introduces them in the policy process, whilst the 'policy process' is taken to mean both the policy debates and the content of the measures finally adopted. A WPA may (or may not) adopt the demands of the feminist movement and it can either include or exclude these demands in the policy process. Table 1 shows that four possibilities exist regarding the dependent variable, i.e. the way in which the performance of the WPA relates to the feminist movement. First, when the WPA adopts the demands of the movement and includes them in the policy process, the WPA is a 'full ally' of the movement. Second, when the WPA adopts the demands of the movement but does not
} 
Table 1 Types of policy performance of a women's policy agency (WPA) in relation to the feminist movement

\begin{tabular}{|c|c|c|c|}
\hline & & \multicolumn{2}{|c|}{$\begin{array}{l}\text { The WPA adopts the demands of the } \\
\text { feminist movement? }\end{array}$} \\
\hline & & Yes & No \\
\hline The WPA includes demands in the policy process? & $\begin{array}{l}\text { Yes } \\
\text { No }\end{array}$ & $\begin{array}{l}\text { Full ally } \\
\text { Symbolic ally }\end{array}$ & $\begin{array}{l}\text { Independent actor } \\
\text { Outsider }\end{array}$ \\
\hline
\end{tabular}

include any specific demand in the policy process, the WPA is a 'symbolic ally' of the movement. Third, when the WPA does not adopt the demands of the movement, but includes other demands in the policy process, the WPA is an 'independent actor'. Fourth, when the WPA neither adopts the demands of the movement nor includes any demand in the policy process, the WPA is an 'outsider' of the policy process.

\section{The Explanatory Factors}

What factors can explain the type of policy performance of a WPA in relation to the feminist movement? The literature on social movements, gender equality institutions and policies, and public policy suggests at least three types of explanatory factor: the characteristics of the feminist movement; the characteristics of the WPA; and the political context.

Regarding the characteristics of the feminist movement, some of the literature on gender equality institutions (also called 'state feminism') identifies a correlation between the pressure exercised by the women's movement and WPAs' most successful campaigns (Friedman 2000, p. 74; Stetson \& Mazur 1995, p. 290). More concretely, other things being equal, the higher the priority given to an issue by the feminist movement and the more cohesive or united it is around certain demands, the higher the probability that it will successfully pressurize the WPA to adopt its demands and attempt to include them in the policy process (Lovenduski 2005, pp. 283-284, 292; Mazur 2001, p. 23; Outshoorn 2004, pp. 17, 291; Stetson 2001, p. 295).

With respect to the characteristics of the WPA, at least three of its features make the WPA more prone to act as a policy ally of the feminist movement. The relevant literature suggests that, other things being equal, the higher the priority given to an issue by the WPA and the greater the material and human resources of a WPA, the more advanced the activity of the WPA is, including its activities on behalf of the demands of the feminist movement (Baldez 2001, p. 18; Mazur 2001, p. 305; Outshoorn 2004, pp. 284, 291; Rai 2003, pp. 27-28). The 'resource mobilization' perspective also proposes that the resources of social and political actors influence their policy impact (McCarthy \& Zald 1977; Zald 1992, p. 332). Third, the proximity of a WPA leadership to the feminist movement is also significant. For example, if the leadership of the WPA is close to the movement and knows its demands, then it is much more motivated to advance 
them in the policy arena (Franceschet 2003, pp. 12-13; Lovenduski 2005, p. 273; Outshoorn 2004, pp. 284, 291; Stetson 2001, p. 295).

As regards the political context, two factors seem to determine whether a WPA acts as a policy ally of the feminist movement or not: the ideological position of the party in office, and the structure of the policy area. The literature on state feminism argues that, in general, left-wing parties in power help WPAs to act as allies of the feminist movement to a greater extent than conservative parties (Baldez 2001; Lovenduski 2005, p. 285; Stetson 2001, p. 295). The thesis that the ideological 'colour' of parties matters is congruent with the 'political process' approach. This proposes that in contemporary polities the structural and conjunctural characteristics of the state influence social movements over time, causing their goals, strategies, organizational features, and even outcomes to develop in particular ways (Kriesi 1996; McAdam 1982; Tarrow 1996).

As far as the structure of the policy area is concerned, the literature on public policy argues that policy areas differ regarding the actors that participate in the policymaking process (Heclo 1978, pp. 88, 102-103; Jordan 1981). If one imagines policy areas along a continuum, one would find at one extreme what the literature terms 'iron triangles', that is, policy areas where only very few powerful actors, who are relatively independent from the general political context, participate. At the other extreme, one would find 'networks' or loose policy areas where many actors take part in the decision-making process at different stages, and where it is not easy to determine which actors are the most powerful. It is important note that the majority of gender equality agencies do not have the power and resources to administer most gender equality policies. Rather, gender equality agencies are usually in charge of lobbying other state units to initiate gender equality measures. Therefore, it is reasonable to argue that, other things being equal, the more open a policy area is to the intervention of various social and political actors, the easier it will be for a WPA to participate in that area, and by extension to take part in it as an ally of the feminist movement (Lovenduski 2005, p. 284; Mazur 2001, pp. 299-300; Outshoorn 2004, p. 291; Stetson 2001, pp. 286, 289-290).

\section{The Empirical Case}

The empirical case studied in this article is the WPA of the Spanish central state: the Women's Institute (Instituto de la Mujer, WI). It was created in 1983; six years after the first democratic elections were held in Spain and one year after the electoral victory of the Partido Socialista Obrero Español (PSOE). The study begins in 1983, when the WI was created, and takes us up to 2003. According to the WI act of foundation and its regulations, the main WI objective is to promote policy initiatives for women. The WI has neither the power nor the budget to formulate and implement most gender equality policies. Instead, it has to convince other state offices to elaborate women's equality policies. The WI is an administrative unit currently attached to the Ministry of Labour and Social Affairs and has its own director, staff (around 170 members), 
facilities, and budget. Since its establishment, its budget has almost constantly increased. In 2006, its annual budget was €26,250,000 (El País, 28 September 2005, p. 67). The WI has been in existence without interruption since 1983 under governments of different ideological persuasions: the social-democratic PSOE (1983-96 and 2004 onwards) and the conservative Partido Popular (PP) (19962004). In spite of its late establishment in comparison with WPAs in other Western countries, the WI is now comparable to those institutions in terms of personnel, budget, and the extent of its functions (Jones 1995; Threlfall 1996, p. 124; 1998).

In order to assess the extent to which the WI has been a policy ally of the feminist movement, this article analyses policy debates that fulfil four conditions:

(1) debates have taken place in public arenas such as the legislature, courts, news media, political party conferences or electoral campaigns; (2) occurred in periods when a women's policy agency, the WI, was in existence; (3) represented the range of discussions on the issue in Spain; and (4) ended up with an official decision, including for instance, legislation, an executive order, a court ruling or a government policy proposal. (Research Network on Gender Politics and the State 2005, pp. 24-25)

This article studies policy deliberations on: job training (JT), abortion (A), prostitution $(\mathrm{P})$, and political representation $(\mathrm{PR})$. These four policy areas are related to areas of social life where marked gender inequalities are in existence: education and work (job training); reproduction (abortion); sexuality (prostitution); and decisionmaking (political representation). The debates analysed here fulfil the aforementioned four conditions.

The role played by the WI in hot issues (HIs), or the most controversial political matters in the country, that are not perceived as gender conflicts by major social and political actors are also studied. From the 1990s, unemployment and terrorism have regularly been considered as HIs by the majority of adult Spaniards. Other concerns that have also been recognized as hot topics, but to a lesser extent and/or during a shorter period than unemployment and terrorism, include housing, immigration, drugs, and crime (Centro de Investigaciones Sociológicas 1990-2003). An illustration of an HI debate, selected for study in this article, is the deliberation around the attempt to reform the system of unemployment benefits that took place in 2002-3.

It is the analysis of the 12 debates that this article now turns to. Various sources have been used, such as parliamentary debates, press files, opinion polls, and documents produced by the WI and the feminist movement, political parties and other organizations. For each debate, the discussion, the policy role played by the WI vis-àvis the feminist movement, and the explanatory factors are succinctly presented.

\section{Job Training $(1983-97)^{1}$}

Debate 1 (JT1): The 1985 National Plan on Job Training (1985), 1983-85²

In the context of Spain's entry into the European Community (EC) in 1986, policymakers knew that the European Social Fund financed up to 65 per cent 
of occupational training activities in EC member states, provided that member states financed the remaining part. However, Spain would risk missing this opportunity to receive European money, as, until the adoption of the National Plan in 1985, no comprehensive job training policy was in place.

The various feminist groups did not take a public stance on this issue. However, feminists within the women's departments of the main trade unions- the Partido Comunista de España (PCE) affiliated CCOO (Comisiones Obreras/Workers' Commissions) and the PSOE-affiliated UTG (Unión General de Trabajadores/Workers' General Union) — expressed very general views on job training and gender. ${ }^{3}$ For instance, feminist trade unionists drew attention to the fact that: more men than women participated in job training courses; women over 30 years did not really engage in job training courses due to family responsibilities; women tended to take part in courses related to traditionally female professions, such as secretaries; and occupational training was of little use to women in finding a job or in improving individual job prospects. The WI neither made public any concrete position on the National Plan nor expressed any general view on job training, and it did not participate in the policy process that culminated in the National Plan. Therefore, the role played by the WI in debate 1 was that of an 'outsider'.

As for the explanatory factors, job training reform was a low priority for the feminist movement as a whole. Feminist trade unionists were in agreement in defending the very general view that job training policy had to be more womenfriendly. Job training was also a topic of low priority for the WI. The WI budget and staff were low up to 1989-90 and high afterwards. The leadership of the WI was close to the feminist movement, since the WI director between 1983 and 1988 (Carlota Bustelo) and some members of the WI directorate were former members of the movement (Threlfall 1998, p. 85). The left (PSOE) was in government albeit the policy area was closed to the intervention of the WI. In general, the constellation of actors that participate in job training policy formation is firmly restricted to the Ministry of Labour, the principal trade unions, and the main employers' organizations.

Debate 2 (JT2): The Creation of the General Council for Professional Training (1986), $1985-86$

The General Council for Professional Training (Consejo General de la Formación Profesional) or 'General Council' was created in January 1986. Its purpose was to advise the government on occupational (and vocational) training. It also elaborated its own policies, since it regularly proposed and approved a plan on professional (and vocational) training, and controlled its implementation. Its composition clearly represented the tripartite nature of the job training policy establishment, with a total of 36 representatives, 13 each from state, labour, and management.

The feminist movement did not elaborate any public position on the creation of the General Council. As in debate 1, feminist trade unionists expressed the same very general views on job training. The WI remained silent on the issue, and did not 
participate in the policy deliberation that ended with the establishment of the General Council. Therefore, the role played by the WI was that of an 'outsider'.

Unsurprisingly, given the similar time frame of the two debates, the explanatory factors are very much the same as for debate 1 . Nevertheless, the structure of the policy area requires further elaboration. In Spain, when policies are articulated through legislative Acts, members of Parliament (MPs) automatically participate in the decision-making process. The 1986 Act was approved after a relatively short parliamentary discussion. Parliament is, generally considered, a policy area open to the intervention of various social and political actors, including the WI. It is true that Parliament has some characteristics of closed policy environments: parliamentary proceedings are codified through regular meetings and rules, and participation is limited to leaders of political parties with parliamentary representation. However, parliamentary debates are public and social and policy actors outside Parliament can follow the discussions and put pressure on parliamentarians and party leaders in general. The WI can help the government with parliamentary work. But in the case of job training issues, the policy sub-field usually remains impenetrable to actors outside state authorities, organized labour, and management. Parties with presence in Parliament are not the main actors in the policy sub-field of job training. Therefore, the policy area of debate 2 was closed.

Debate 3 (JT3): The 1992 and 1996 Agreements and the Reform of the General Council for Professional Training (1997), 1986-97

In the early 1990s, it was clear that in previous decades in-work training had been neglected in favour of the training of the unemployed. That was somewhat understandable given the double-digit unemployment rates. However, in 1992 and 1996, several agreements were signed by the state and the social partners which gave incentives for firms to train their workers. During the 1990s, powers to manage job training programmes were transferred from the central state to some regions. In 1997, Act 19 of 9 June reformed the composition of the General Council for Professional Training, including in it representatives from the regions.

There was no evidence of feminist groups advancing concrete demands regarding the 1992 and 1996 agreements or the 1997 reform of the General Council. Meanwhile, feminist trade unionists defended the general views on job training and gender already advanced in debates 1 and 2. From the late 1980s, the WI was more active on job training policy issues than before. For instance, in 1988, the WI organized a workshop on 'Job Training from the Women's Point of View' (Instituto de la Mujer 1989). In this workshop, WI officials defended the views expressed by feminist trade unionists and subsequently adopted the positions of the movement. Nevertheless, the WI did not participate in the policy deliberation previous to the 1992 and 1996 agreements and the 1997 reform of the General Council. Therefore, the WI acted as a 'symbolic ally' of the movement in this deliberation. 
Regarding the explanatory factors, the feminist movement as a whole conferred a low priority on job training and was united on its very generic points of view. The WI gave a medium priority to job training. The staff and budget of the WI were already high. Up to spring 1996, the WI leadership was close to the movement: its first three directors were leading members of the feminist movement. After its electoral victory of spring 1996, the conservative PP appointed a civil servant with no links with the feminist movement as director of the WI (Threlfall 1998, pp. 85-88; Valiente 2006, p. 49). The debate under analysis now unfolded between 1986 and 1997. The WI leadership was close to the movement, and the left was in power but for the same reasons as during previous debates the policy area of job training was closed to the intervention of actors like the WI.

\section{Abortion $(1983-98)^{4}$}

\section{Debate 4 (A1): Partial Decriminalization of Abortion (1985), 1983-85}

The 1944 Penal Code defined abortion as a crime in all circumstances. A partial decriminalization of abortion took place in 1985 (hereafter, the '1985 Abortion Act'). Since then, abortion has been a crime punishable under the Penal Code with three exceptions: when the woman has been raped; when pregnancy seriously endangers the physical and mental health of the mother; and when the foetus is deformed.

Most groups in the Spanish feminist movement have been united in calling for abortion on demand since the 1970s, when Spanish feminists first mobilized on this issue in favour of decriminalizing abortion (Sundman 1999). In the mid-1980s, the WI leadership also supported abortion on demand. But the WI hardly engaged in the deliberation prior to the 1985 abortion Act (Barreiro 1998, 228). The debate under study here began eight months before the establishment of the WI, when the Socialist Party presented a bill in Parliament to partially decriminalize abortion. During the early period of the debate the WI did not exist and in the later stages it formally existed but was still in the process of formation. Thus the WI had little opportunity to participate in the debate. By adopting a position on the issue allied with the feminist movement but hardly taking part in the policy discussion that led to the 1985 abortion Act, the WI acted as a 'symbolic ally' of the feminist movement.

As for the explanatory factors, abortion was an issue of high priority for the movement as a whole, and the movement was united in advocating abortion on demand. Abortion was also a high-priority issue for the WI, whose budget and staff were low in the mid-1980s. WI leadership was close to the movement. The left was in power, and, since the deliberations took place in Parliament, the policy area was (relatively) open to the intervention of various social and political actors.

Debate 5 (A2): The Regulations of the 1985 Abortion Act (1986), 1985-86

The rules involved in the implementation of the abortion legislation are very important, because they determine whether access to abortion services is easy 
or difficult for women (Outshoorn 1996, p. 150). In summer 1985, the Ministry of Health established the first regulations of the 1985 Abortion Act. These consisted of the material and human resources required in clinics for the performance of abortion, and a very broad conscience clause for health personnel (Barreiro 1998, pp. 238-241).

The WI monitored the implementation of the first regulations of the 1985 Abortion Act, and identified at least two main problems. First, due to the excessive resources required, very few public and no private clinics were performing abortions. Second, the breadth of the conscience clause meant that very few abortions were actually performed in the very few public hospitals with adequate facilities (Barreiro 1998, pp. 244-246). The WI made recommendations, to the Ministry of Health, to solve the aforementioned problems (PSOE Secretaría Confederal de Participación de la Mujer 1989). Responding to some degree to these recommendations, the government eventually approved the 1986 Royal Decree, which replaced all previous regulations. This made access to abortion easier by cutting back on the material and human resources required for clinics to have the right to perform 'low-risk abortions', that is, up to 12 weeks of pregnancy. As expected, private clinics became interested in becoming authorized centres for performing abortions, and indeed since then have performed the overwhelming majority of abortions (96 per cent in 2004-El País, 27 December 2005, p. 22).

The policy content of the 1986 Royal Decree, as it was de facto implemented, partly coincided with the goals of the feminist movement, without fully satisfying them. Most feminist groups favoured abortion on demand, which was not provided by the 1986 Royal Decree. Nevertheless, the loose implementation of the 1986 Royal Decree made it possible in practice to use the mental health clause as an (imperfect) proxy for abortion on demand (Barreiro 1998, pp. 248-252; Blofield 2006, p. 92). Thus, by adopting the demands of the feminist movement, and (partially) including them in the policy process, the WI acted as a 'full ally' of the movement.

As for the explanatory factors, these were unchanged from the first debate on abortion. Regarding the policy area, the Ministry of Health was the principal actor. Since its establishment, the WI had, however, made conscious efforts to build institutional channels of communication with other state units, including the Ministry of Health. There were periodic meetings between the members of the WI directorate and personnel of the Ministry of Health to discuss a variety of matters, including abortion. Thanks in part to these WI institution-building efforts, the policy environment around the regulation of the implementation of the 1985 Abortion Act was (moderately) open to state feminist activism.

\section{Prostitution $(1983-2000)^{5}$}

Debate 6 (P1): The Treatment of Prostitution in the 1995 Penal Code (1995), 1994-95

Broadly speaking, Spanish legislation on prostitution was abolitionist from 1963. In this abolitionist vein, prostitutes were not legally defined as criminals. In contrast, 
people who promoted the prostitution of others or benefited from it were defined as criminals and punished accordingly_ by up to six years in prison. Such abolitionist legislation considered prostitution an affront to people's dignity; it was then irrelevant whether prostitutes voluntarily consented to prostitution or not. The ultimate goal of abolitionist policy is that women stop working as prostitutes (Carracedo 2001, pp. 151-154).

The abolitionist legislation did not change with the transition to democracy and the consolidation of the democratic regime. The Penal Code of 1995 reformed Spanish legislation on prostitution, distancing it from the abolitionist past as it decriminalized behaviours around prostitution that had been considered crimes in the past (such as pimping). The only behaviour around prostitution that was still defined as a crime was the promotion of the prostitution of minors or of those legally defined as incapacitated.

Up to the late 1980s, most members of the Spanish feminist movement interested in prostitution defended the abolitionist position. But around the late 1980s, some Spanish feminists began to argue that there are two types of prostitutes: those who perform this task voluntarily and those who are forced into prostitution by others. They proposed that the state should actively fight forced prostitution but not free prostitution. These feminists conceptualized free prostitutes as sex workers and demanded that the state treat them in the same way as other workers, for example by allowing them to contribute to the social security system (Garaizábal 1991).

The WI position on prostitution has tended to coincide with that of the abolitionist sector of the feminist movement. This coincidence was reflected for example in the First Gender Equality Plan that was implemented between 1988 and 1990 (Instituto de la Mujer 1988, pp. 33-34). ${ }^{6}$

As previously pointed out, the 1995 Penal Code contained anti-abolitionist reforms that could not have come from the WI. Thus, by adopting the position of the abolitionist branch of the feminist movement but not including it in the policy process, the WI acted as a 'symbolic ally' of this branch of the movement.

As for the explanatory factors, in the mid-1990s prostitution was an issue of low priority for the feminist movement as a whole. The part of the movement interested in prostitution was itself divided because some activists were abolitionists while others defined prostitution as sex work. Prostitution was also an issue of low priority for the WI, whose staff and budget were high at the time, and whose leadership was close to the movement. The left was in power, and the policy area was (relatively) open because the reform took place in Parliament.

\section{Debate 7 (P2): The 1999 Reform of the Penal Code Regarding Prostitution (1999), 1997-99}

The 1995 Penal Code regarding prostitution was revised in 1999. This 1999 reform increased the punishment for crimes relating to the prostitution of minors and legally incapacitated people. A new crime was defined: that of trafficking people with the aim 
of sexually exploiting them. The 1999 revision increased the penalties for prostitution crimes committed by criminal organizations.

As has been already explained, the WI adopted the position of the abolitionist branch of the feminist movement. In addition, the Third Gender Equality Plan (1997-2000) recommended in very general terms the adoption of measures to eliminate the trafficking of women with the aim of sexually exploiting them (Instituto de la Mujer 1997, pp. 73-74, 78). This recommendation coincides with the definition of the crime of trafficking women with the purpose of forcing them into prostitution of the 1999 reform of the Penal Code. But the remaining measures on prostitution included in the 1999 reform do not coincide with the WI position on prostitution. Thus, by adopting the abolitionist point of view but not fully including it in the policy process, the WI acted as a 'symbolic ally' of the abolitionist branch of the feminist movement.

Regarding the explanatory factors, prostitution was a low-priority issue for the movement as a whole, and the movement was deeply divided on that topic. Prostitution was also a low-priority issue for the WI, whose budget and staff were high from 1989 to 1990, and whose leadership was distant from the movement. The conservative PP was in power, and the 1999 reform of the Penal Code was made in Parliament, which is a policy area open in principle to the (indirect) intervention of the WI.

\section{Debate 8 (P3): The Prostitution Measures of the Immigration Act (2000), 1998-2000}

Article 55 of the immigration Act of January 2000 offered permanent residence and work permits to illegal immigrants trafficked into Spain and forced into prostitution provided they denounce their traffickers or cooperate with public authorities in the prosecution of these traffickers.

In relation to the WI, the Third Gender Equality Plan (1997-2000) contained proposal number 7.3.2: 'to study the viability of the establishment of a temporary residence permit for victims of traffic forced into prostitution who have shown willingness to testify in legal processes [against their traffickers]' (Instituto de la Mujer 1997, p. 79). With article 55 of the Immigration Act, legislators not only fulfilled this proposal but went further, by offering work and residence permits to some victims of trafficking. The WI successfully pressurized law-makers to incorporate this proposal into state legislation. ${ }^{7}$ Feminist groups active in the policy area of prostitution agreed with the proposal and article 55. Thus, the WI's role vis-à-vis the feminist movement was that of a 'full ally'. Given the similar time frame of previous debates on prostitution, the explanatory factors were the same.

\section{Political Representation $(1983-2003)^{8}$}

Debate 9 (PR1): Endorsement of a 25 Per Cent Women's Quota in the Socialist Party (1988), 1987-88

In the first four democratic elections (1977, 1979, 1982, and 1986), the proportion of women members of the Congress of Deputies was around six per cent, while that 
of women members of the Senate was even lower; the proportions of PSOE women deputies and senators were never higher than nine per cent. But as a result of intense pressure from party feminists, the 31st PSOE federal congress in January 1988 passed a 25 per cent women's quota for party positions and electoral lists. Subsequently, the proportion of PSOE female deputies increased to reach 27.7 percent in 1996. The proportion of PSOE female senators increased to 17.9 percent in 1993, but decreased to 10.5 percent in 1996 (see Instituto de la Mujer 1994; 2007).

During the transition to democracy, some feminists thought that an important level of formal and real equality could be attained through state action. Thus, it was important that women were present in political decision-making arenas. Other feminists rejected mainstream politics altogether, because they saw the state as a site that actively contributed to the perpetuation of unequal gender relations. At the end of the 1970s, the feminist movement was bitterly split between supporters of those positions. However, this division eroded slightly during the 1980s and more in the 1990s (Gallego 1994, p. 671; Jenson \& Valiente 2003).

For the WI, the small number of women in political decision- making was a problem that had to be solved with active measures. Thus, the WI adopted the position of the sector of the feminist movement interested in political representation. Some members of the WI directorate pushed demands for women's political representation into the PSOE debate on quotas. These WI officials could do so because they belonged (or had belonged) to the party, the WI, and the feminist movement (Threlfall 1996, p. 120). In sum, by supporting the position of the sector of the feminist movement active in pursuing political representation and including it in the 1987-88 PSOE debate, the WI acted as a 'full ally' of the aforementioned sector of the movement.

Regarding the explanatory factors, the goal of an increase in women's political decision-making was of medium priority for the feminist movement as a whole. The sector interested in political representation was moderately united in its support for quotas (Jenson \& Valiente 2003). An increase in women's political representation was also an issue of medium priority for the WI in 1987-88. Staff and budget were low and its directorate was close to the movement. The PSOE was in power and, since the 25 per cent quota was an internal PSOE rule, the policy area of this measure was the PSOE. It was moderately open to the intervention of the WI, because the WI director and some members of the WI directive team belonged to the Socialist Party.

\section{Debate 10 (PR2): Endorsement of a 40 Per Cent Women's Quota in the Socialist Party (1997), 1992-97}

Again as a consequence of sustained lobbying from party feminists, delegates at the 34th PSOE federal congress (20-22 June 1997) discussed and approved the increase of both internal and electoral women's party quota to 40 per cent. Subsequently, the proportion of women who became PSOE deputies increased to 36.8 percent in 2000 and 46.3 per cent in 2004. The proportion of women who became PSOE senators increased to 17.4 per cent in 2000 and 27.1 per cent in 2004 . 
This second debate on political representation ran across two different political periods: between 1992 and spring 1996 (Socialist rule); and between spring 1996 and June 1997 (conservative rule). Until the 1996 electoral defeat by PSOE, the WI incorporated the feminist movement's goal of quotas into its own positions, leading many activities on the matter both in the domestic context and abroad (Jenson \& Valiente 2003, pp. 87-88). The WI leadership also advanced the aim of the 40 per cent quota within the Socialist Party. As in the previous debate, this was possible because all WI directors and some of its high-ranking officials were either leading members or close to the PSOE and the movement.

In spring 1996, the PP came to power. After its electoral victory, the WI did not adopt movement goals (quotas). This is reflected in the main WI policy document of the late 1990s: the Third Gender Equality Plan (Instituto de la Mujer 1997). After the 1996 election, the WI leadership did not participate in the PSOE decision-making process, because leading WI officials belonged (or were close) to the PP.

In sum, the debate on the endorsement of a 40 percent women's quota in the Socialist Party lasted between 1992 and 1997. During most of this time (up to spring 1996), the WI acted as a full ally of the sector of the movement interested in political representation.

Regarding the explanatory variables, political representation was an issue of medium priority for the feminist movement as a whole, and the sector of the movement interested in political representation was consistent in its support for quotas. Up to spring 1996, political representation was an issue of high priority for the WI. During the whole debate, its staff and budget were high, directors were close to the movement, the left was in power, and the policy area was (moderately) open to its intervention.

Debate 11 (PR3): The 2001 Socialist Bill on Mandatory Quotas for All Parties (2003), 1997-2003

In November 2001, again in response to intense pressure from PSOE feminists, the PSOE submitted a bill to reform the 1985 General Electoral Act in order to mandate a 40 per cent women's quota for all political parties. The bill was debated and rejected in Parliament on 8 April 2003.

Since the late 1990s, the sector of the feminist movement interested in political representation has continuously mobilized in favour of higher proportions of women in political decision-making through mandatory quotas. After the 1996 PP electoral victory, the WI did not support quotas. In the late 1990s, the PP coined the expression: 'balanced' participation and/or representation (Jenson \& Valiente 2003, p. 92). This was included in the Third and Fourth Gender Equality Plans elaborated during PP rule (Instituto de la Mujer 1997, p. 55; 2003, pp. 23-25). Balanced participation and/or representation means supporting an increase in the number of women occupying high political positions but without specifying what such an increase numerically means. This would be achieved either by adopting no specific measures or alternatively by undertaking measures different from quotas, such as research on the issue, or providing training for potential female decision-makers. ${ }^{9}$ Thus, the WI played the role 
of an 'independent actor' from the feminist movement, because they did not adopt the demand of the movement (mandatory quotas) but participated in the debate on the 2001 Socialist bill defending other goals (balanced participation and/or representation).

Regarding the explanatory factors, political representation was an issue of medium priority for the feminist movement as a whole, and it was united in its support for quotas. In contrast, political representation was an issue of low priority for the WI, whose staff and budget were high, and whose leadership was distant from the movement. All WI directors under conservative rule lacked ties with the feminist movement. The right was in power, and the policy area (Parliament) was (moderately) open to the intervention of the WI.

\section{Unemployment Protection}

Debate 12 (HI): The Attempt to Reform the System of Income Protection for Unemployed Individuals (2002-3), 2002-3

In spring 2002 the PP announced that at least four aspects of the unemployment protection system would be reformed, albeit in a restrictive way: the circumstances under which unemployed individuals receiving unemployment benefits could reject job offers; non-contributory means-tested unemployment benefits for short-term agrarian workers living in the regions of Andalusia and Estremadura; income protection for dismissed workers who sue their employers on the grounds of illegal dismissal; and income protection for people who work discontinuously for the same employer under permanent contracts. In opposition to this reform project, unions called a general strike on 20 June 2002. The governmental proposal was reflected in Royal Decree Law 5/2002 but some months after the partially successful general strike, the government gave in. Act 45/2002 and Royal Decree Law 426/2003 reestablished a system of unemployment protection very similar to that already in existence.

Generally speaking, the feminist movement joined forces with the unions and the left in their demand for the complete withdrawal of the governmental project rather than advancing their own requests (Valiente 2006, p. 117). At least one female trade unionist with a high feminist profile participated in the meetings of organized labour and government representatives. However, it seems that she did not attempt to advance any specific feminist claim in the negotiations with governmental policymakers. ${ }^{10}$

The WI did not take any public position on the 2002-3 attempt to reform unemployment protection, and remained silent during the whole policymaking process. The Third and Fourth Gender Equality Plans and the WI webpage did not say anything on the reduction of unemployment benefits (Instituto de la Mujer 1997; 2003). El País did not document any WI activities regarding the 2002-3 unemployment reform. Thus, the WI was an 'outsider' to the policy process.

In relation to the explanatory factors, unemployment reform was an issue of medium priority for the feminist movement in its entirety. The overwhelming 
majority of Spanish feminists since the 1970s have thought that access to employment in equal terms to men is a basic ingredient of the struggle for women's liberation. However, in general the movement has not been a major policy actor on employment (and unemployment) issues, for instance, regarding chief job training policies. In the debate now under study, the movement was cohesive in asking the government to withdraw its proposed reform.

Because of the lack of a publicly known WI position on the unemployment reform, it is reasonable to affirm that unemployment reform was an issue of low priority for the WI. In 2002-3, WI staff and budget were high and WI leadership was distant from the feminist movement. The conservative party was in power between 1996 and 2004. The policy area around employment and unemployment issues was closed to the intervention of political and social actors other than organized labour and management, specialized state officials, and to a lesser extent parties with parliamentary representation.

\section{Results: Answering the Research Question}

Table 2 summarizes the results of the dependent variable: the types of policy performance of the WI in relation to the feminist movement between 1983 and 2003. As can be seen in Table 2, in a third of the cases (4/12), the WI was a 'full ally' of the

Table 2 Types of policy performance of the WI (1983-2003)

\begin{tabular}{ll}
\hline Position of the policy performance of the WI & Debates \\
\hline Full ally & A2, P3, PR1, PR2 \\
Symbolic ally & JT3, A1, P1, P2 \\
Independent & PR3 \\
Outsider & JT1, JT2, HI \\
\hline
\end{tabular}

Notes:

A1: Abortion, debate 1: partial decriminalization of abortion (1985), 1983-85

A2: Abortion, debate 2: regulations of the 1985 Abortion Act (1986), 1985-86

HI: Hot issue: attempt to reform the system of unemployment protection (2002-3), 2002-3

JT1: Job training, debate 1: 1985 National Plan (1985), 1983-85

JT2: Job training, debate 2: creation of the General Council for Professional Training (1986), 1985-86

JT3: Job training, debate 3: 1992 and 1996 agreements and the reform of the General Council for Professional Training (1997), 1986-97

P1: Prostitution, debate 1: Penal Code (1995), 1994-95

P2: Prostitution, debate 2: reform of the Penal Code (1999), 1997-99

P3: Prostitution, debate 3: Immigration Act (January 2000), 1998-2000

PR1: Political representation, debate 1: 25 per cent quota in the PSOE (1988), 1983-88

PR2: Political representation, debate 2: 40 per cent quota in the PSOE (1997), 1992-97

PR3: Political representation, debate 3: 2001 Socialist bill on mandatory quotas for all parties (2003), 1997-2003. 
feminist movement: the WI adopted the demands of the movement and introduced them in the policy process. These four cases are the policy debates that culminated in: the 1986 regulations of the 1985 Abortion Act (A2); the treatment of prostitution by the 2000 Immigration Act (P3); the 1988 endorsement of a 25 per cent women's quota in the Socialist Party (PR1); and the 1997 endorsement of a 40 per cent women's quota also in the Socialist Party (PR2).

In another third of the cases (4/12), the WI acted as a 'symbolic ally' of the feminist movement as it adopted the demands of the movement but did not include any demand in the policy process. These four cases are the policy deliberations that culminated with the 1992 and 1996 agreements on job training and the 1997 reform of the General Council for Professional Training (JT3); the 1985 partial decriminalization of abortion (A1); the treatment of prostitution in the 1995 Penal Code (P1); and the 1999 reform of the 1995 Penal Code regarding prostitution (P2).

The WI acted as an 'independent actor' from the feminist movement in only one case: the debate around the 2001 Socialist bill on mandatory quotas for all parties (PR3). The WI did not adopt the demand of the movement (quotas), but introduced in the policy process another notion, that of balanced participation and/or representation, which explicitly excludes quotas.

Finally, in a quarter of cases (3/12), the Women's Institute acted as an 'outsider' to the policy process: the WI neither adopted the demands of the movement nor included any demand in the policy process. These three cases are the policy discussions that culminated in: the adoption of the 1985 National Plan on job training (JT1); the 1986 creation of the General Council for Professional Training (JT2); and the HI of the 2002-3 attempt to reform the system of unemployment protection (HI).

\section{Results: The Explanatory Factors}

What can explain the different types of WI policy performance in relation to the feminist movement? Table 3 shows the explanatory factors for the 12 policy debates analysed in this article. As shown in Table 3, in most debates in which the WI was a 'full ally' of the feminist movement (A2, PR1, PR2), both the movement and the WI gave a high (or medium) priority to the issue under discussion. Seen from the opposite perspective, in all but three of the cases in which the WI acted as a 'symbolic ally' of the movement, as an 'outsider' of the policy process, or as an independent actor, the topic under discussion was a low priority for both the movement and the WI. Therefore, generally speaking, one of the necessary but insufficient conditions for the WI to act as a 'full ally' of the feminist movement was that the matter debated by policymakers was a high (or medium) priority concern for both the movement and the WI. This finding is congruent with the proposition defended by part of the literature on state feminism, which supports the notion that WPA and movement priorities matter when explaining the policy behaviour of the WPA on behalf of the movement.

The finding that priorities make a difference is not surprising. Gender equality institutions are very small state units in charge of an immense task: to advance the 
Table 3 Explanatory factors of the policy performance of the WI in relation to the feminist movement (1983-2000)

Movement characteristics

+ Issue priority

High: A2, A1

Medium: PR1, PR2, PR3

Low: P3, JT1, JT2, JT3, P1, P2, HI

+ Movement cohesion

United: A2, PR1, PR2, JT1, JT2, JT3, A1, PR3, HI

Divided: P3, P1, P2

WI characteristics

+ Issue priority

High: A2, PR2, A1

Medium: PR1, JT3

Low: P3, JT1, JT2, P1, P2, PR3, HI

+ Budget and staff

High: P3, PR2, JT3, P1, P2, PR3, HI

Low: A2, PR1, JT1, JT2, A1

+ Proximity of the WI leadership to the movement

Close: A2, PR1, PR2, JT1, JT2, JT3, A1, P1

Distant: P3, P2, PR3, HI

Note: The debates where the WI acted as a full ally of the movement appear first and in bold.

status of half of the population (women). A small institution pursuing huge tasks can only be effective if it focuses intensively on some issues and perseveres in them. Similarly, the feminist movement strives for a gigantic aim-to eliminate gender inequality-and only manages to convert gender equality institutions into its political allies in the causes that are central for it and around which it mobilizes endlessly.

In all cases in which the Women's Institute acted as a 'full ally' of the feminist movement, the policy area was open to the intervention of various social and political actors including the WI. Therefore, this article identifies a second necessary (but not sufficient) condition for the WI to act as a 'full ally' of the movement, namely the (open) structure of the policy area. This finding supports a proposition defended by the literature on public policy and the policy process approach to the study of social movements. According to this proposition, the features of the policy environment intensively influence the performance of social and political actors.

Table 3 also shows the factors that in general are useful, albeit not necessary, for the WI to act as a 'full ally' of the feminist movement: a united movement around certain demands; the proximity of the WI leadership to the movement; and the left in power. It is true that these three factors were, almost, always present in the cases in which the WI acted as a 'full ally' of the feminist movement. Nevertheless, the feminist movement was also united in six out of the nine cases in which the WI was not a full ally of the movement (JT1, JT2, JT3, A1, PR3, HI). Moreover, the WI leadership was close to the movement and the left was in power in five of the nine cases in which the WI was not a 'full ally' of the movement (JT1, JT2, JT3, A1, P1). Seen from another 
perspective, a cohesive movement, a WI leadership close to the movement, and the left in power did not by themselves determine that the WI behave as a full ally of the movement if the issue under discussion was of low priority for both the movement and the WI, and the policy area was close to the intervention of various social and political actors including the WI. This finding indicates that the literature on gender equality institutions (and policies) and social movements should temper the importance of the cohesion of the feminist movement, the proximity of leadership of gender equality institutions to the movement, and the left in power.

As for the budget and staff of the WI, in two of the cases in which the WI acted as a 'full ally' of the feminist movement the material and human resources of the agency were high (P3, PR2), but in the remaining two cases were low (A2, PR1). Moreover, in five (JT3, P1, P2, PR3, HI) of the eight cases in which the WI did not act as a 'full ally' of the movement the WI budget and staff were high. However, few resources are not an insurmountable obstacle for gender equality agencies to act as full allies of the movement if the issue discussed in the policy process is of high priority for both the movement and the agency, and the policy area is open to the intervention of various actors including the gender equality agency. Resources matter, but to a smaller extent than that proclaimed by the literature on state feminism and the resource mobilization perspective.

In sum, a contingent 'yes' is the answer for the Spanish central state to the question: Are gender equality agencies effective allies of the feminist movement in the policy arena? In a third of the policy debates studied in this article, the WI adopted the demands of the feminist movement and introduced them in the policy process. In general, the WI could act in this way if the issue discussed by policymakers was a priority for both the movement and the WI, and the policy area was open to the intervention of various social and political actors. Three other factors facilitated, but were not necessary, for the WI to act in this way: the cohesion of the movement around certain demands; the proximity of the WI leadership to the movement; and the left in power.

\section{Acknowledgements}

This article contains the results on Spain of a comparative research project undertaken under a frame elaborated by the Research Network of Gender and the State (2005). I would like to thank the editor of this issue, John Karamichas, and two anonymous reviewers for their helpful comments on an earlier draft.

\section{Notes}

[1] The last year examined is 1997 because the fieldwork for the analysis of job training debates ended in January 1998. The focus here is on job training policy issues and does not analyse vocational training. The description of the three job training debates follows closely Valiente (2001a).

[2] The sub-headings for all debates follow the same structure: the number of the debate ('debate 1' in this case), the acronym of the debate, the name of the debate, the year of the measure with which the debate ended, and the period under which the debate evolved. 
[3] Since the appearance of the second wave of feminist activism in Spain, an important number of activists have acted as feminists within trade unions. Therefore, the women working in the women's departments of unions are considered as part of the feminist movement in this article.

[4] The last year examined is 1998 and the account of the two abortion debates closely follows Valiente (2001b).

[5] The last year examined is 2000 and the description of the three prostitution debates closely follows Valiente (2004).

[6] A Gender Equality Plan is a policy instrument whose formulation is coordinated by the WI. It contains gender equality measures to be applied during a given period by some ministries. In Spain, four central state Gender Equality Plans have been applied, between 1988 and 1990, 1993 and 1995, 1997 and 2000, and 2003 and 2006 (Instituto de la Mujer 1988, 1993, 1997, 2003).

[7] Interview with D. Pérez-Herrera, General Secretary of the Women’s Institute, Madrid, 19 April 2002.

[8] The period under study here concludes in 2003 and the account of the three debates on political representation closely follows Valiente (2005).

[9] Interview with Pérez-Herrera; interview with R. Barrios, advisor to the People's Party on social affairs in the Congress of Deputies, Madrid, 27 April 1999.

[10] For the analysis of debate 12, the coverage of the debate in the daily edition of El País, between 12 April 2002 and 12 April 2003, has also been used.

\section{References}

Baldez, L. (2001) 'Coalition politics and the limits of state feminism in Chile', Women \& Politics, vol. 22, no. 4 , pp. $1-28$.

Barreiro, B. (1998) Democracia y Conflicto Moral, Instituto Juan March de Estudios e Investigaciones, Madrid.

Blofield, M. (2006) The Politics of Moral Sin, Routledge, New York.

Carracedo, R. (2001) 'Legislación penal española', in Simposio Internacional Sobre Prostitución y Tráfico de Mujeres con Fines de Explotación Sexual, ed. Dirección General de la Mujer de la Comunidad de Madrid, Madrid, pp. 149-159.

Centro de Investigaciones Sociológicas (1990-2003) Barometer Surveys, < www.cis.es $>$ (accessed 13 April 2007).

Franceschet, S. (2003) "'State feminism" and women's movements: the impact of Chile's Servicio Nacional de la Mujer on women's activism', Latin American Research Review, vol. 38, no. 1, pp. 9-40.

Friedman, E. J. (2000) 'State-based advocacy for gender equality in the developing world: assessing the Venezuelan national women's agency', Women \& Politics, vol. 21, no. 2, pp. 47-80.

Gallego, M. T. (1994) 'Women's political engagement in Spain', in Women and Politics Worldwide, eds B. Nelson \& N. Chowdhury, Yale University Press, New Haven and London, pp. 661-673.

Garaizábal, C. (1991) 'La prostitución: un debate abierto', in Prostitución: Debate y Propuestas del Movimiento Feminista, ed. Forum de Política Feminista, Madrid, pp. 6-10.

Heclo, H. (1978) 'Issue networks and the executive establishment', in The American Political System, ed. A. King, American Enterprise Institute, Washington, pp. 87-124.

Instituto de la Mujer (1988; 1993; 1997; 2003) First, Second, Third, and Fourth Gender Equality Plans, Madrid.

Instituto de la Mujer (1989) La Formación Ocupacional desde la Perspectiva de las Mujeres, Madrid. Instituto de la Mujer (1994) Las Mujeres en Cifras: una Década, 1982-1992, Madrid.

Instituto de la Mujer (2007) 'Las mujeres en cifras', < www.mtas.es/mujer/mujeres/cifras/> (accessed 13 April 2007). 
Jenson, J. \& Valiente, C. (2003) 'Comparing two movements for gender parity: France and Spain', in Women's Movements Facing the Reconfigured State, eds L. A. Banaszak, K. Beckwith \& D. Rucht, Cambridge University Press, Cambridge, UK, pp. 69-93.

Jones, A. B. (1995) 'Spain's Institute for Women', European Journal of Women's Studies, vol. 2, no. 2, pp. $261-269$.

Jordan, A. G. (1981) 'Iron triangles, woolly corporatism and elastic nets: images of the policy process', Journal of Public Policy, vol. 1, no. 1, pp. 95-123.

Kriesi, H. (1996) 'The organizational structure of new social movements in a political context', in Comparative Perspectives on Social Movements, eds D. McAdam, J. D. McCarthy \& M. N. Zald, Cambridge University Press, Cambridge, UK, pp. 152-184.

Lovenduski, J. (ed.) (2005) State Feminism and Political Representation, Cambridge University Press, Cambridge, UK.

Mazur, A. G. (ed.) (2001) State Feminism, Women's Movements, and Job Training, Routledge, New York.

McAdam, D. (1982) Political Process and the Development of Black Insurgency, 1930-1970, University of Chicago Press, Chicago.

McCarthy, J. D. \& Zald, M. N. (1977) 'Resource mobilization and social movements: a partial theory', American Journal of Sociology, vol. 82, no. 6, pp. 1212-1241.

Outshoorn, J. (1996) 'The stability of compromise: abortion politics in Western Europe', in Abortion Politics, eds M. Githens \& D. M. Stetson, Routledge, New York, pp. 145-164.

Outshoorn, J. (ed.) (2004) The Politics of Prostitution, Cambridge University Press, Cambridge, UK.

PSOE Secretaría Confederal de Participación de la Mujer (1989) Seminario sobre el aborto, 4 de julio de 1989, Madrid.

Rai, S. M. (2003) 'Institutional mechanisms for the advancement of women: mainstreaming gender, democratizing the state?', in Mainstreaming Gender, Democratizing the State?, ed. S. M. Rai, Manchester University Press, Manchester and New York, pp. 15-39.

Research Network on Gender Politics and the State (2005) Project description, < http://libarts.wsu. edu/polisci/rngs/working.html> (accessed 30 May 2006).

Stetson, D. M. (ed.) (2001) Abortion Politics, Women's Movements, and the Democratic State, Oxford University Press, New York.

Stetson, D. M. \& Mazur, A. G. (eds) (1995) Comparative State Feminism, Sage, Thousand Oaks, CA.

Sundman, K. (1999) Between the Home and the Institutions, Acta Universitatis Gothoburgensis, Gothenburg.

Tarrow, S. (1996) 'States and opportunities: the political structuring of social movements', in Comparative Perspectives on Social Movements, eds D. McAdam, J. D. McCarthy \& M. N. Zald, Cambridge University Press, Cambridge, UK, pp. 41-61.

Threlfall, M. (1996) 'Feminist politics and social change in Spain', in Mapping the Women's Movement, ed. M. Threlfall, Verso, London, pp. 115-151.

Threlfall, M. (1998) 'State feminism or party feminism? feminist politics and the Spanish Institute of Women', European Journal of Women's Studies, vol. 5, no. 1, pp. 69-93.

Valiente, C. (2001a) 'A closed subsystem and distant feminist demands block women-friendly outcomes in Spain', in State Feminism, Women's Movements, and Job Training, ed. A. G. Mazur, Routledge, New York, pp. 111-130.

Valiente, C. (2001b) 'Gendering abortion debates: state feminism in Spain', in Abortion Politics, Women's Movements, and the Democratic State, ed. D. M. Stetson, Oxford University Press, New York, pp. 229-245.

Valiente, C. (2004) 'State feminism and central state debates on prostitution in post-authoritarian Spain', in The Politics of Prostitution, ed. J. Outshoorn, Cambridge University Press, Cambridge, UK, pp. 205-224. 
Valiente, C. (2005) 'The women's movement, gender equality agencies and central-state debates on political representation in Spain', in State Feminism and Political Representation, ed. J. Lovenduski, Cambridge University Press, Cambridge, UK, pp. 174-194.

Valiente, C. (2006) El Feminismo de Estado en España, Universitat de València, Valencia.

Zald, M. N. (1992) 'Looking backward to look forward: reflections on the past and future of the resource mobilization research program', in Frontiers in Social Movement Theory, eds A. D. Morris \& C. M. Mueller, Yale University Press, New Haven, pp. 133-155. 